\title{
Justifying Unparticipated Causality in Proclus
}

July 17, 2015 - 6th Int'l. PG Ancient Philosophy Conference (University of Edinburgh)

Jonathan Greig (LMU / Munich School of Ancient Philosophy)

jonathan.greig@lrz.uni-muenchen.de

1. Unparticipated/Participated Entities for Proclus (Description)

2. Problem: Unparticipated as a Superfluous Cause or Efficient Cause?

3. Efficient Causality for Proclus

3.1. Efficient Cause as Greater/Transcending its Effect

3.2. Aristotelian Background on Efficient Causality

3.3. Aristotle in Agreement with Plato? Neoplatonic Reappropriation

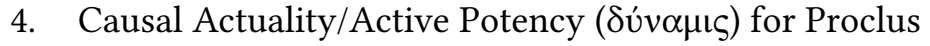

4.1. Actuality as distinct from Active Potency

4.2. Efficient Causality Necessitating Middle Term: Transmission of Potency ( $\delta \dot{v} v \alpha \mu \varsigma)$

5. Confirmation: the Unparticipated as a Primary Efficient Cause

5.1. Unparticipated-Participated as Analogous to Primary/Instrumental Eff. Causes

\section{Unparticipated/Participated Entities for Proclus}

[T1] Proclus, Elements of Theology, Prop. 23

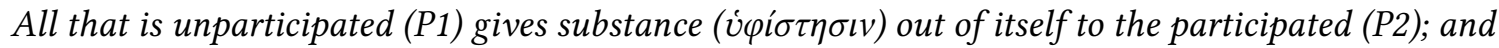
all participated substances (P2) are linked upwards to unparticipated existences (P1).

(A) For on the one hand the unparticipated, having the relative status of a monad (as being its own [5] and not another's, and as transcending the participants), ${ }^{1}$ generates terms which are able to be participated. For either it will remain fixed in sterility and by itself, and so may not have honour; or else it will give something from itself, whereof the receiver becomes a participant, whilst what is given attains substantial existence as a participated term.

(B) Every participated term, on the other hand, becoming a property ( $\tau \iota v \grave{s} \varsigma$ ) of that by which it is participated, is secondary to that which in all is equally present and has filled them all out of itself. [10] For that which is in one is not in the others; while that which is present to all alike, that it may illuminate all, is not in [any] one, but is prior to them all. For either it is in all, or in one out of all, or prior to all. (B1) But a principle which was in all [15] would be divided amongst all, and would itself require a further principle to unify the divided; and further, all the particulars would no longer participate the same principle, but this one and that another, through the distribution of its unity. (B2) And if it be in one out of all, it will be a property no longer of all but of one. Inasmuch, then, as it is both common to all that can participate and identical for all, (B3) it must be prior to all: [20] that is, it must be unparticipated. (trans. Dodds, modified)

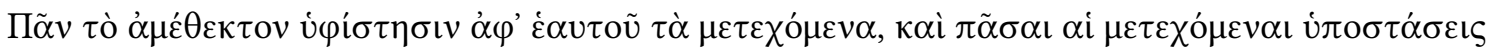

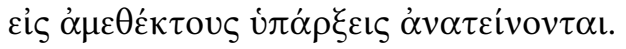

\footnotetext{
${ }^{1}$ Established in the previous ET Prop. 21: 'Every order has its beginning in a monad and proceeds to a manifold co-ordinate therewith; and the manifold in any order may be carried back to a single monad' (trans. Dodds).

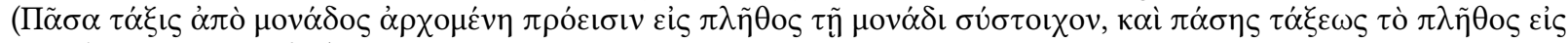

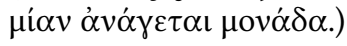




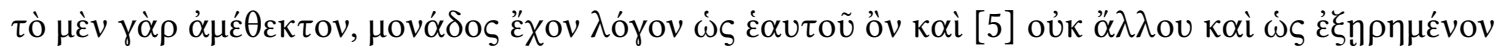

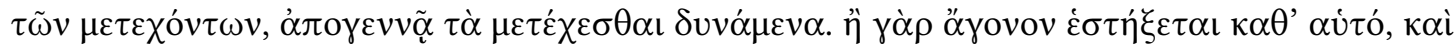

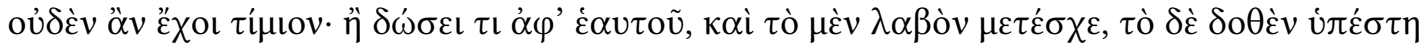
$\mu \varepsilon \tau \varepsilon \chi 0 \mu \dot{\varepsilon} v \omega \varsigma$.

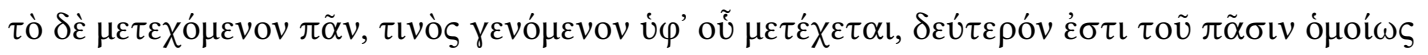

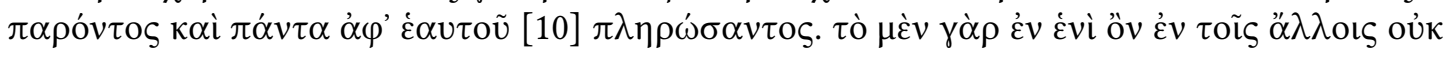

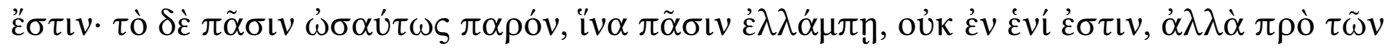

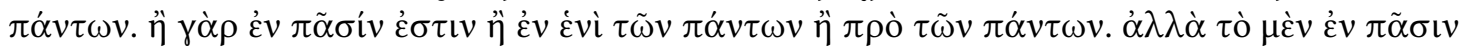

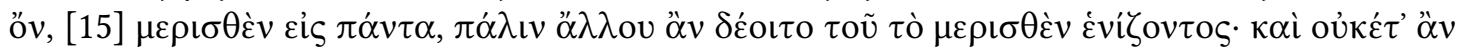

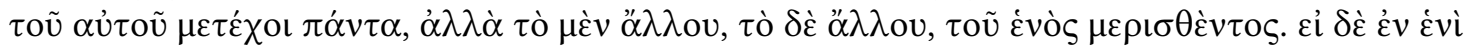

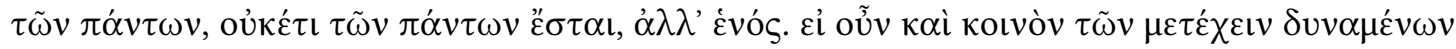

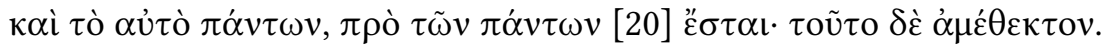

The proposition is split into two parts-(A) and (B). (A) argues for the unparticipated term as productive. This suggests that Proclus wants to move away from the idea of the unparticipated merely being

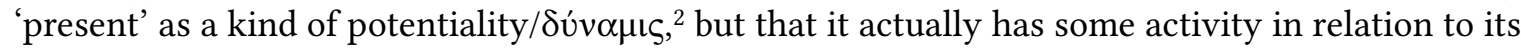
participants. Thus it 'gives' something $(\tau \iota)$ of itself to the participants. ${ }^{3}$

(B) provides the initial justification for the unparticipated's role:

1. Every participated term (P2) directly corresponds to its participating individual (P3).

1.1. Therefore, 'in' one only, and not all, by definition.

2. (P2) is secondary to the unparticipated (P1).

2.1. For something is (B1) 'in all', (B2) 'in one', or (B3) neither senses of 'in'-before all.

2.1.1. If (B1)-taken literally, divided between all. Another principle needed to unite.

2.1.1.1. 'In all' may refer to the sum total of all participated (P2) terms-if so, this is an extra argument for 'some other principle'.

2.1.2. If (B2)-logically not in all, but belonging to one particular, like the participated term (P2).

2.1.3. Therefore, (B3)-before all.

2.2. Out of (B1)-(B3), (B1) cannot stand in for 'that which is present to all alike', since the latter does not imply division, for Proclus, as the former does.

So to list a particular example of [T1]'s principles:

[T2] Commentary on Parmenides, 628.36-39 (Cousin)/628.26-27 (Steel)

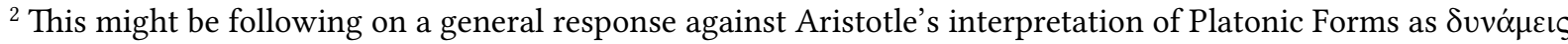

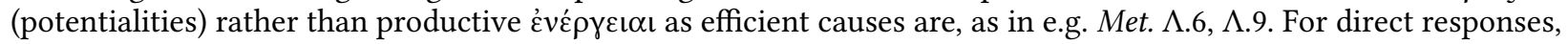
see e.g. Syrianus, In Metaph. [...].

${ }^{3}$ Cf. e.g. Elements of Theology Prop. 18: 'Everything which by its existence bestows a character on others itself

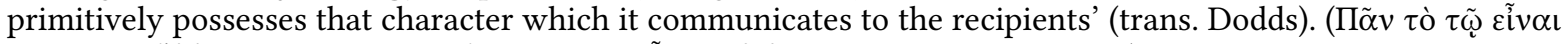

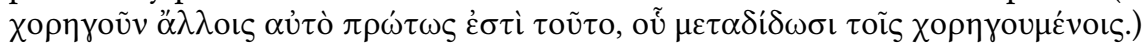


[...] for intellect is either universal (ó $\lambda \iota \kappa o ́ \varsigma)$ and unparticipated, or universal (ö $\lambda \circ \varsigma)^{4}$ and

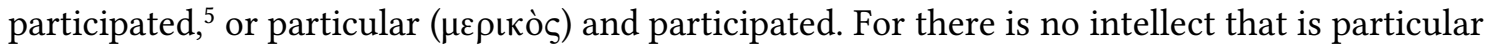
( $\mu \varepsilon \rho \iota \kappa o ̀ \varsigma)$ and unparticipated. (trans. Morrow/Dillon)

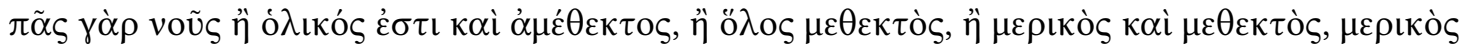

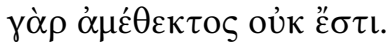

Some things to note about the nature of the unparticipated and participated:

- The unparticipated is not correlated to the participants (P3) in the same way that the participated entities (P2) are.

- One-to-one correspondence between each particular participated entity (P2) and participant (P3).

- However, what the nature of (P2) is in relation to (P3) is not clear-immanent or ontologically distinct? (Likely the latter, as a participated entity)

- One-to-many correspondence between the unparticipated (P1) and participated (P2) (and implicitly participant (P3))

- [By implication, individual, participated soul, although having separate existence, could not be unparticipated (P1) relative to the body as participant (P3).]

\section{Problem: Unparticipated as a Superfluous Cause or Efficient Cause?}

Proclus describes the participated terms (P2) coming from the unparticipated (P1). However, as absolutely transcendent over its participants and therefore disconnected, (P1) has no relation to the participants (P3) except mediately through (P2). ${ }^{6}$ If $(\mathrm{P} 2)$ is directly correlated to (P3) in a way (P1) is not, ${ }^{7}$ what role does $(\mathrm{P} 1)$ play?

In this respect, the line between 15-20 in Proclus' response to (B1) is important: 'all the particulars would no longer participate the same principle, but this one and that another, through the distribution of its unity'.

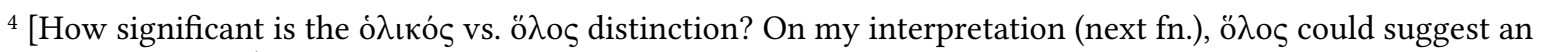
abstract sense of 'universal', applying to all participants generally, whereas ó $\lambda$ ıкó e.g. the unparticipated as the locus of universal application.]

${ }^{5}$ Tentatively, I take this ('universal and participated') to be the potency issued from the unparticipated (adapting ET Prop. 81-which I'll explicitly consider later in this paper), which is the same for all participated entities (P2) and participants (P3). The power issued becomes converted into each distinct participated entity (P2), which then falls into the 'particular and participated' category-for instance, particular soul's relation to a particular body.

${ }^{6}$ Cf. De Rijk (1994) 18-9: 'Hence the following picture arises: out of itself, not qua partaking, that is, of something else superior to it, the unshareable generates shares which attain subsistence by participation and each uniquely belong to their own participant. This would mean, I presume, that the privative noun $\alpha \mu \varepsilon \theta \varepsilon$ ć $\tau$ o any notion of sharing actually accomplished both in the upward and in the downward direction, so that qua unshareable the unshareable is independent of any superior source of participation and transcends the entities coming after it.'

${ }^{7}$ Contra Dodds (1963) 211, who conceives of an essential linking between the unparticipated and participated; see De Rijk (1994) 1: 'Most unfortunately Dodds joins (ibid.) Emile Bréhier in suggesting that "the $\dot{\alpha} \mu \dot{\varepsilon} \theta \varepsilon \kappa \tau$ ov is the intension of the concept, the $\mu \varepsilon \tau \varepsilon^{\prime} \chi 0 v \tau \alpha$ are its extension, and the $\mu \varepsilon \tau \varepsilon \chi 0$ o $\mu \varepsilon \nu \alpha$ are that which links intension with extension". Rosán is quite right in rejecting such a comparison.' In this case, the proposed problem is the reverse: an un-essential link between unparticipated and participated.
} 
- This seems to be saying that participated entities (P2) are not of the same kind, but entirely distinct. E.g.: your participated humanity is, strictly speaking, distinct from my participated humanity; ${ }^{8}$ the commonality in the two is derived from a separate, unparticipated Form of 'Man'.

Two views of unparticipated (P1) and participated (P2) terms' causality:

1. Strong view - (P2) as efficient cause / (P1) only as paradigmatic: (P1) is merely the guarantor of 'unity'-e.g. paradigmatic cause. Efficient causality of (P3) lies with (P2).

- Reasons for strong view: each participant (P3) is directly informed by (P2). (P1)'s existence merely ensures the collective unity of (P2) as one of a kind, but has no essential role in the causation of (P3).

- e.g. ET Prop. 80, where body is properly acted on by the immanent incorporeal which acts on it -thus, individual soul (P2) is responsible for action on the living body (P3). Monadic, unparticipated Soul (P1) plays no direct role here in this process. ${ }^{9}$

- Internal tension in ET Prop. 23: talk about (P1) generating (P2) is then superfluous, if (P2) is sufficient as a complete efficient cause of (P3).

- Therefore: Prop. 23 (and other proofs for the unparticipated) won't work if (P1) adds nothing to the causal explanation of (P2) and (P3).

2. Weak view - (P2) as an analogous 'instrumental' efficient cause / (P1) as primary efficient cause

- (P2) is not a sufficient as primary efficient cause for (P3), but rather is the 'individual determiner' for (P1)'s action on (P3). (P2) then only has a sub-ordinate role in efficient causality, serving as an instrumental cause of $(\mathrm{P} 1)$.

Ultimately I want to defend the weak view as a justification for unparticipated causality. In this model, I read the unparticipated (P1) as a primary efficient cause in relation to (P3).

\title{
3. Efficient Causality for Proclus
}

\section{Efficient Cause as Greater/Transcending its Effect ${ }^{10}$}

\author{
[T2] Proclus, Elements of Theology, Prop. 7
}

\footnotetext{
${ }^{8}$ In conversation with Peter Adamson, this conception of universals-at this point, without reference to the unparticipated-mirrors trope theory. Lowe (2002) 361-2: 'The trope theorist holds that the blueness of a particular blue chair is something that really exists just as much as the chair itself does, but that it is not something that can be identified with the blueness of any other blue chair, even if the two chairs resemble each other exactly in respect of the colour that each of them has. In short, on this view, each blue chair possesses its own distinct property of blueness, which is a particular, just as the chair itself is a particular.' Cf. Stanford Encyclopedia of Philosophy on 'Tropes': http://plato.stanford.edu/entries/tropes/.

${ }^{9}$ Elements of Theology Prop. 80, 74.27-30 (Dodds ed.): 'The proper nature of all bodies is to undergo action

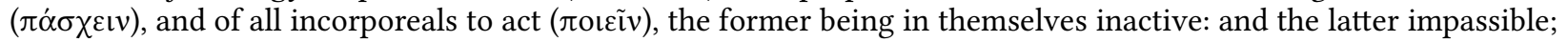
but through association with the body the incorporeal too undergoes action, even as through participation of the

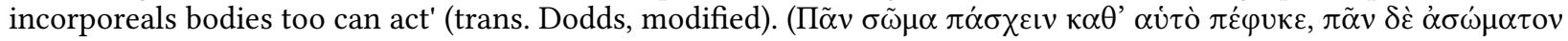

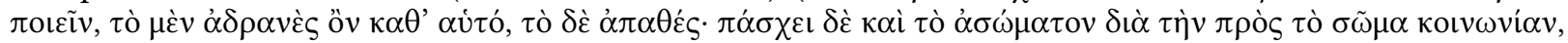

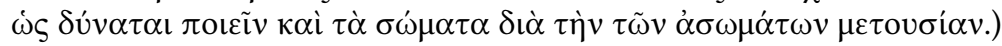

${ }^{10}$ See Lloyd (1976) for an analysis of Proclus' argument in ET Prop. 7, and a general history of the concept. 
[Proposition:] Every productive cause of another is greater than the nature of the produced thing. (trans. mine)

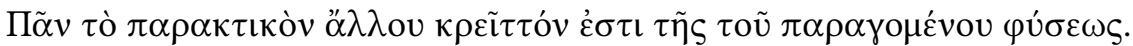

In this, Proclus is making a universal claim about productive/efficient causes-they are necessarily greater by nature than their effects. Now, here one might dispute Proclus and say, look: fire produces fire; man produces man; etc-yet the nature of none of these is greater than that which is produced. However, peeling back how Proclus is understanding this requires looking at distinctions in efficient causes-specifically between primary and instrumental causes. Proclus is almost certainly thinking of the former compared to the latter.

\section{Antecedents for the Efficient Cause's Superiority}

To begin with the Platonic context, the Timaeus gives us the background of this distinction between primary causes ( $\alpha i \tau i \alpha)$ and contributory, or instrumental, causes ( $\sigma v v \alpha i \tau i \alpha-$ literally, 'con-causes'). ${ }^{11}$ Whereas the latter do not have the full 'reason' or shape of what happens compared to true causes, true, primary causes ( $\alpha i \tau i \alpha)$ like the soul (e.g. of the craftsman) have the final reason why in causation. Philebus 27a8-9 makes a more straightforward distinction by stating that what is subservient to the cause ( $\tau$ ò $\delta o v \lambda \varepsilon \tilde{v} o v . . . \alpha i \tau i \underline{\alpha})$ is not the same as the cause ( $\alpha i \tau i \alpha) .{ }^{12}$

Now if we look at Aristotle, there may be initial reason to deny that this is the case with every efficient cause:

[T4] Aristotle, Physics II.3, 194b30-32

Again, the primary source (or 'principle') of the change or rest, as the man who deliberated is a cause, the father of the child, and generally what makes of what is made and what changes of what is changed. (trans. Hardie/Gaye, modified)

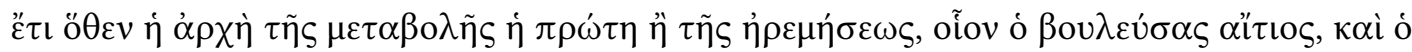

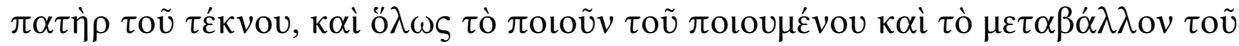
$\mu \varepsilon \tau \alpha \beta \alpha \lambda \lambda \mathrm{o} \mu \dot{c}^{\mathrm{v}} \mathrm{ov}$.

[T5] ibid., 195a21-23

The seed and the doctor and the one who deliberated, and generally the maker, are each the principle from which the change or rest [or motion] originates. (trans. mine)

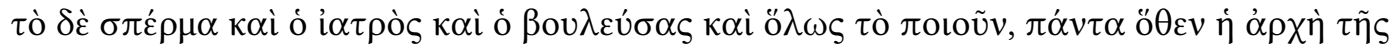

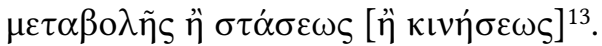

\footnotetext{
${ }^{11}$ Plato, Tim. 46c7-e2: 'Now all of the above are among the auxiliary causes ( $\left.\tau \tilde{\omega} v \sigma v v \alpha i \tau i \omega v\right)$ employed in the service of the god as he does his utmost to bring to completion the character (i $i \delta \varepsilon \alpha v$ ) of what is most excellent. But because they make things cold or hot, compact or disperse them, and produce all sorts of similar effects, most

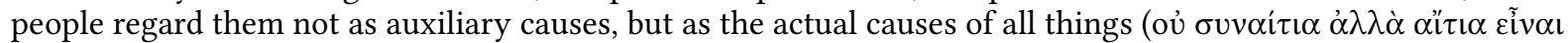
$\tau \tilde{\omega} v \pi \alpha \dot{\alpha} v \tau \omega v)$. Things like these, however, are totally incapable of possessing any reason or understanding about anything. We must pronounce the soul to be the only thing there is that properly possesses understanding. [...] So

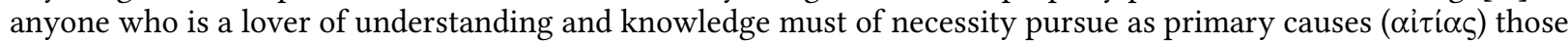
that belong to intelligent nature, and as secondary all those belonging to things which are moved by others and that set still others in motion by necessity' (trans. Zeyl).
}

${ }^{12}$ Proclus draws directly on this in ET, Prop. 75 (line 8), as well as In Tim. I, 298.26, 369.8; In Eucl. 139.20. Cf. Steel (2003) 178, esp. n. 9.

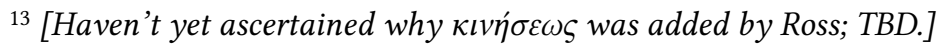


Unlike the Platonic context, Aristotle takes any beginning of motion or generation in some way as an efficient cause. Exactly in what way is irrelevant to the basic definition. By comparison, the Timaeus account (and that of ET Prop. 7) so far holds little currency as a universal rule, when any of these earlier examples each count as an efficient cause.

However, this is not the end of the story: we eventually get a distinction between types of efficient causes-reciprocally affected and non-affected causes-which indicates a concession to the primary/ subordinate types in Plato. First, we should note Aristotle's initial definition of motion from Physics III.1 as the actuality of the potential as potential, ${ }^{14}$ in which model he understands all causation. This leads to the following observation at the end of Physics III.2:

[T6] Aristotle, Physics III.2 202a3-11:

Every mover too is moved, as has been said-every mover, that is, which is capable of motion, and whose immobility is rest (for when a thing is subject to motion its immobility is rest). For to act on [the movable] as such is just to move it. But this it does by contact, so that at the same time it is also acted on. Hence motion is the fulfillment ( $\dot{\varepsilon} v \tau \varepsilon \lambda \varepsilon^{\prime} \chi \varepsilon\llcorner\alpha)$ of the moveable as moveable, the cause being contact with what can move, so that the mover is also acted on. The mover will always transmit a form, either a 'this' or such or so much, which, when it moves, will be the principle and cause of the motion, e.g. the actual man begets [or makes] man from what is potentially man. (trans. Gaye/Hardie, modified)

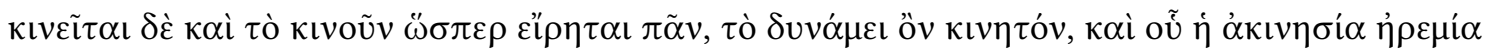

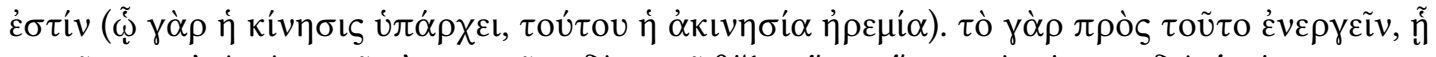

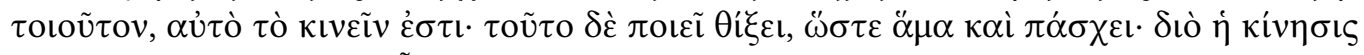

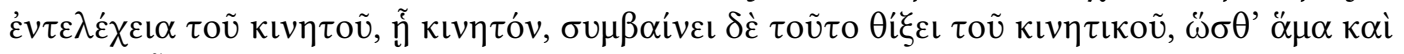

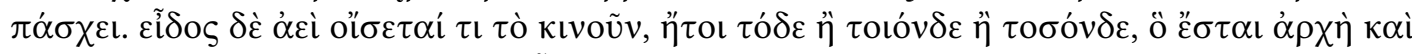

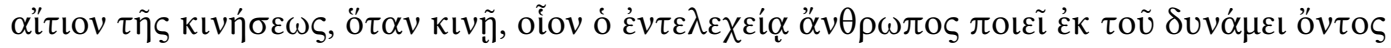

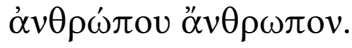

Of immediate impact is the line 'every mover too is moved', since causation happens by 'contact' or 'touch' $\left(\theta^{\prime} \xi_{\varepsilon l}\right)$. So given immediate 'contact' between mover and moved, an immanent relation is necessitated which means the cause itself undergoes reciprocal action: hot water heats the cold stone, but vice versa the cold stone will also cool the hot water. [Fire and cold stone is even better example...] This sense of efficient causality, however, is not the only one Aristotle is content with:

[T7] Aristotle, On Generation and Corruption I.6 323a25-32

As a rule, no doubt, if $\mathrm{A}$ touches $\mathrm{B}, \mathrm{B}$ touches $\mathrm{A}$. For indeed practically all the movers within our ordinary experience impart motion by being moved: in their case, what touches must, and evidently does, touch something which touches it. Yet it is possible-as we sometimes say-for the mover merely to touch the moved, and that which touches need not touch a thing which touches it. Nevertheless it is commonly supposed that touching must be reciprocal, because movers which belong to the same kind as the moved impart motion by being moved. Hence if anything imparts motion without itself being moved, it may touch the moved and yet itself be touched by nothing-for we say sometimes that the man who grieves us touches us, but not that we touch him. (trans. Joachim)

\footnotetext{
${ }^{14}$ E.g. Physics III.1 201b6-15: 'Take for instance the buildable: the actuality of the buildable as buildable is the process of building. For the actuality must be either this or the house. But when there is a house, the buildable is no longer there. On the other hand, it is the buildable which is being built. Necessarily, then, the actuality is the process of building. But building is a kind of motion, and the same account will apply to the other kinds also' (trans. Hardie/Gaye).
} 


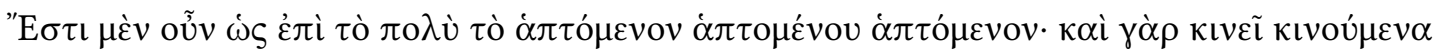

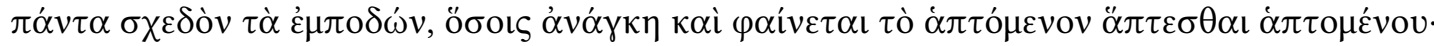

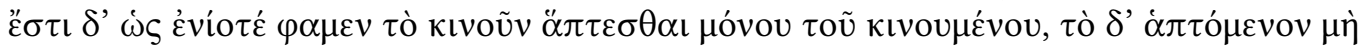

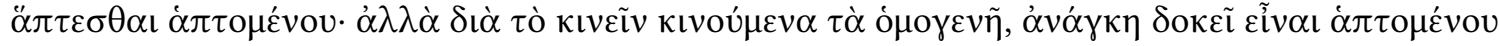

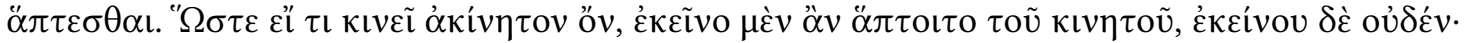

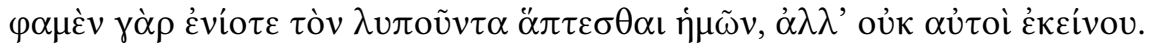

Considered as movers, Aristotle mentions a certain class of efficient causes which are not affected in action on moved/affected things. For instance: the form of health remains unaffected as the first cause of action, while it brings about specific secondary actions: the food, for instance, prescribed by that form which is transformed as it acts on the body. ${ }^{15}$ Later, Aristotle specifies that these kinds of causes do not share the matter which they affect-so implicitly they are immaterial. ${ }^{16}$

The distinction of movers suggests priority, and therefore distinction in nature, between unaffected and affected causes, where enmattered causes imply reciprocity, whereas causes that are not in matter are not affected. What does Aristotle have in mind here? As seen in the earlier example, forms in thinking (like in the case of the deliberator) are one; soul and the unmoved movers of Physics VIII.6-10 and Metaphysics $\Lambda$ also fit this category. Soul as the actuality of life in a potentially-living body fits this category. ${ }^{17}$ The unmoved movers causing the motion of the world spheres in Metaphys. $\Lambda .7-9$, assuming this is seen in line with Physics VIII.10, also fit this category.

Altogether this forms the backdrop for Proclus' appropriation of Aristotle's causal model.

\section{Aristotle in Agreement with Plato? The Neoplatonic Exploitation of Aristotelian Efficient Causality}

Bearing this latter distinction in mind, we can see what led Alexander of Aphrodisias to make the distinction explicit between primary and instrumental efficient causes-exploited, as we will see, by Proclus. Commenting on [T5]:

[T8] Simplicius, On Aristotle’s Physics II, 321.1-12

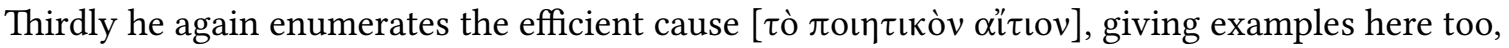
by means of which, I think, he demonstrates the distinctions within the efficient cause, as he did earlier with the material and formal. For the person who has given advice [or who deliberated;

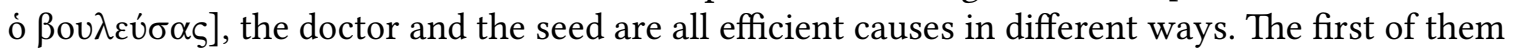

${ }^{15}$ De Gen. et Corr. I.7 324a35-b3: '... thus the art of healing produces health without itself being acted upon in any way by that which is being healed. But the food, in acting, is itself in some way acted upon: for, in acting, it is simultaneously heated or cooled or otherwise affected. Now the art of healing corresponds to an origin, while the

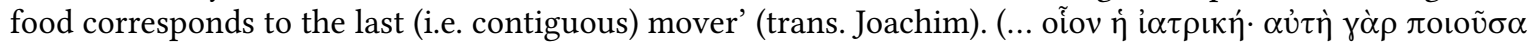

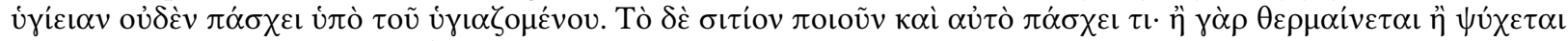

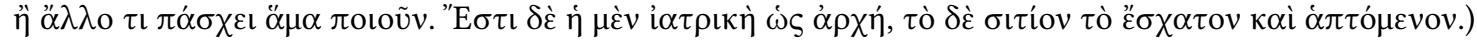

${ }^{16}$ De Gen. et Corr. I.7 324b4-12: 'Those active powers, then, whose forms are not embodied in matter, are unaffected; but those whose forms are in matter are such as to be affected in acting. For we maintain that one and the same matter is equally, so to say, the basis of either of the two opposed things---being as it were a kind; and that which can be hot must be made hot, provided the heating agent is there, i.e. comes near. Hence (as we have said) some of the active powers are unaffected while others are such as to be affected; and what holds of motion is true also of the active powers. For as in motion the first mover is unmoved, so among the active powers the first agent is unaffected' (trans. Joachim). See further the excellent article on efficient causality in De Gen. et Corr. I.6-7 in Buchheim (2007).

${ }^{17}$ De Anima II.2, 414a19ff. By implication, soul as form and actuality of body must be something 'distinct' over and above the material which it forms; see Metaph. Z.17 1041b6ff. Cf. Buchheim (2007) 84--5. 
initiates the process without putting his head to the task; the doctor acts by doing the work himself; but the seed is, in a way, intermediate between the efficient and the material, since it acts by coming-to-be something else through a change to itself; the true agent, as Alexander [of Aphrodisias] agrees, must be distinguished from the product. We should not construe the word 'all' [ $\pi \dot{\alpha} \nu \tau \alpha$, from [T5]] with the word 'acts' [ $\pi$ oเoũv], but should read it separately and take it as referring to the three types of efficient cause. ${ }^{18}$ (trans. Fleet, lightly modified)

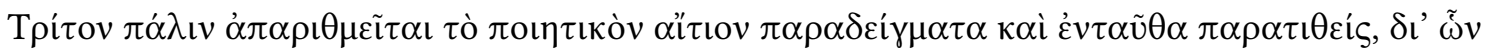

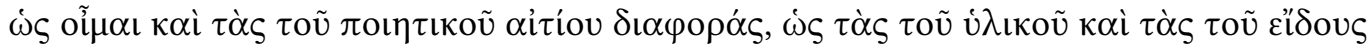

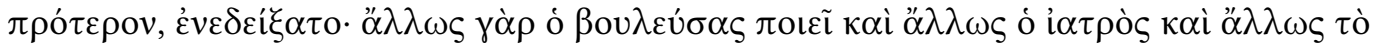

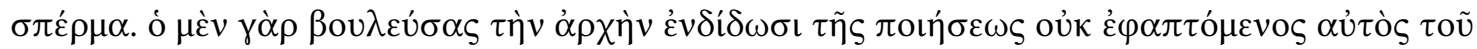

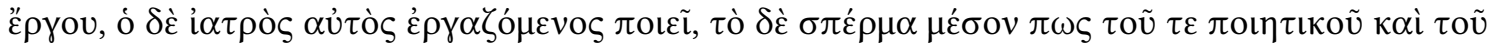

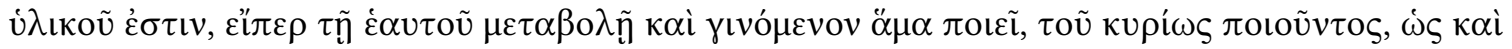
'A $\lambda \dot{\varepsilon} \xi \alpha v \delta \rho \circ \varsigma$ ó $\mu$ o

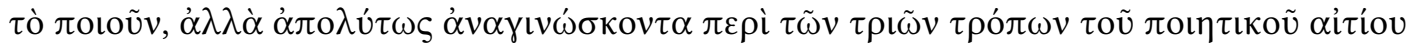
$\dot{\varepsilon} \kappa \delta \dot{\varepsilon} \chi \varepsilon \sigma \theta \alpha \mathrm{l}$.

Aristotle doesn't explicitly bring out these three distinctions (the deliberator (1), doctor (2), and seed (3)), but Alexander likely draws evidence for these distinctions from the different kinds of movers mentioned in Physics VIII.5, with the distinction between moved movers (3), self-movers (2) and unmoved movers (1)-the self-moved man pushing the stick pushing the stone. ${ }^{19}$ What is distinct is Alexander calling the first mover-the unmoved mover (1) - of any motion series a primary efficient cause, which language we do not see in Aristotle.

Proclus almost certainly draws from Alexander for his position in [T2], insofar as the primary efficient cause has priority over the other, subordinate kinds of efficient causes (2 and 3). As such, if we recall what Aristotle said about unaffected causes in [T7], they do not share the same matter of the moved or changed thing. Proclus draws this out more explicitly:

[T9] Proclus, Elements of Theology, Prop. 75

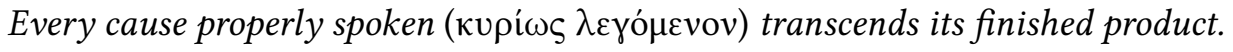

For [if such a cause were] immanent in its effect, either it would be a complementary part of the latter or it would in some way need it for its own existence (prop. 64), and it would in this regard be inferior to the effect. That which exists in the resultant is not so much a cause ( $\alpha i t \tau\llcorner\nu)$

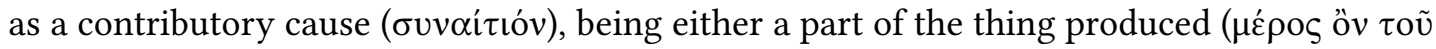

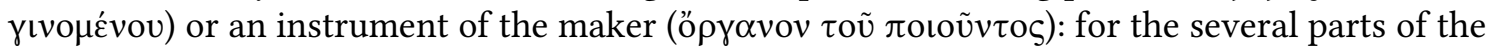
thing exist within it, but are less perfect than the whole; and the instrument serves the maker for the process of production, but is unable to determine for itself the limits of creation. Accordingly every cause properly so called, inasmuch as it both is more perfect than that which proceeds from it (prop. 7) and itself furnishes the limit of its production, transcends the instruments, the elements, and in general all that is described as a by-cause. (trans. Dodds, modified)

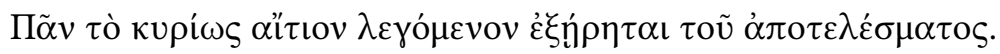

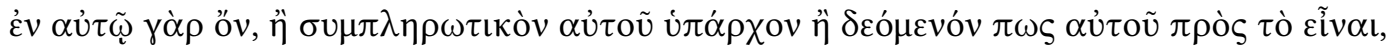

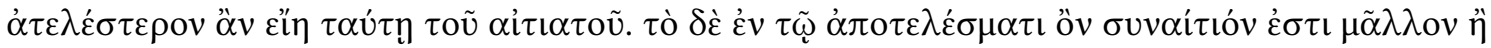

\footnotetext{
18 i.e., from the examples listed, of the person who gave advice, or deliberated (1), the doctor (2), and the seed (3). ${ }^{19}$ Aristotle, Physics VIII.5 256a10-18.
} 


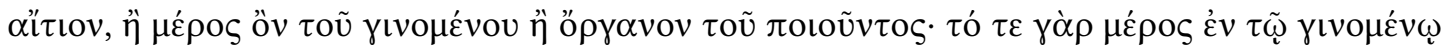

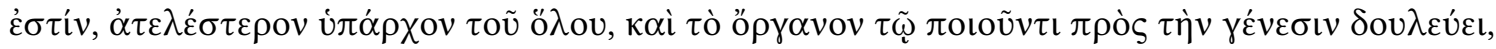

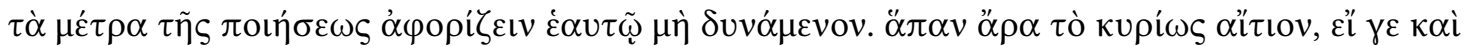

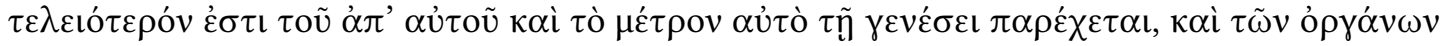

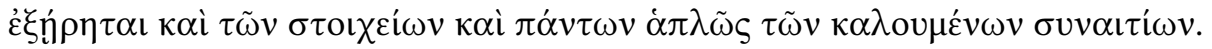

This passage is a further specification of [T2], which follows in line with Alexander/Simplicius' placement of primary efficient causality as distinct from the other moved movers/instrumental causes.

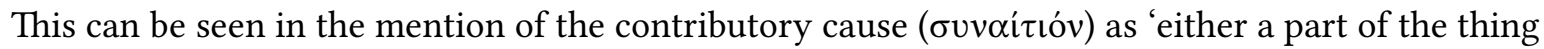
produced or an instrument of the maker'. (Assumedly being 'part of the thing produced' is either the immanent form or matter of the thing.)

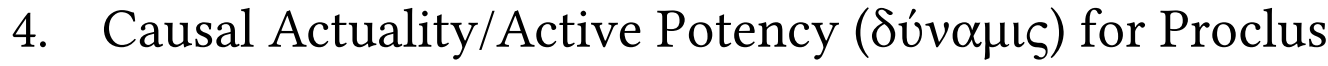

Proclus goes on to adapt Aristotle's causal structure in terms of actuality/potentiality:

[T10] Proclus, Elements of Theology, Prop. 77 (1-11)

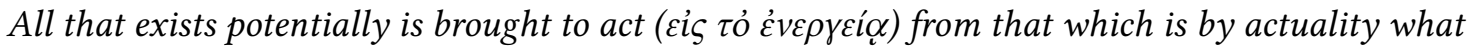
this [the former] is by potentiality: that which is by partial potentiality from that which is partially by actuality what the same by potentiality; and that which is wholly by potentiality from what is wholly according to actuality.

For it is not the nature of that which potentially is to bring itself forward to actuality, being imperfect ( $\alpha \tau \varepsilon \lambda \dot{\varepsilon} \varsigma)$ : for if, being imperfect, it became the cause of its own perfection even by actuality, the cause would be more imperfect than the effect. Thus what is potential, as potential, is not its own cause of being by actuality: for by being imperfect, it will be the cause of perfection, since everything which is by potentiality, as potential, is imperfect, and everything which is by actuality, as actuality, is perfect. (trans. Dodds, modified)

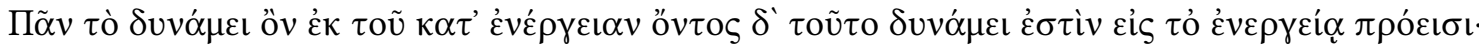

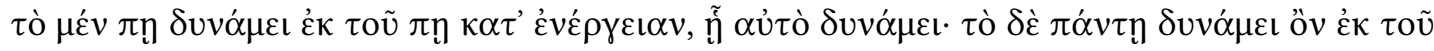

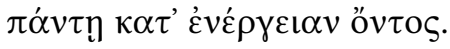

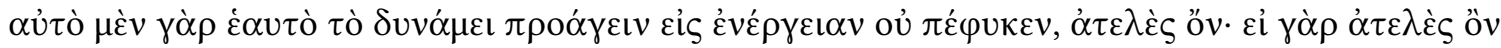

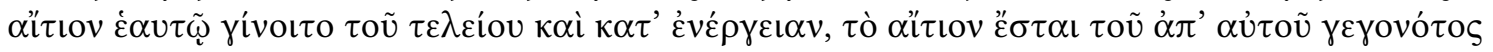

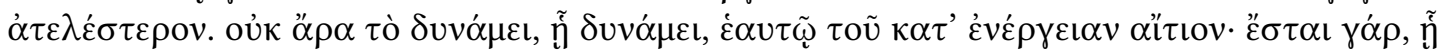

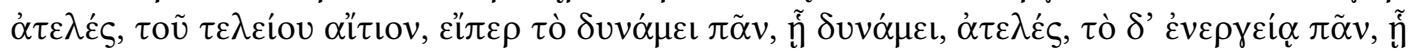

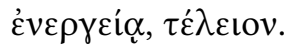


So far, familiar territory coming from Aristotle: this mirrors the definition of motion from the end of Physics III.1 as 'the actuality of the potential as such' in the moved thing, ${ }^{20}$ where the actuality between mover and moved is the same-given that the mover already has the power of effecting change. ${ }^{21} 22$ Proclus, however, makes a shift from Aristotle by emphasizing that every actuality ( $\dot{\varepsilon} v \rho \gamma \varepsilon \dot{\alpha} \alpha)$ proceeds from a given potency/power ( $\delta \dot{v} v \alpha \mu \iota)$ :

[T11] Proclus, Elements of Theology, Prop. 79

\section{All that comes to be arises out of the twofold potency.}

For it should itself be fitted for it and so possess an imperfect potency ( $\delta \dot{v} v \alpha \mu \iota \nu \dot{\alpha} \tau \varepsilon \lambda \tilde{\eta})$; and the producer ( $\tau$ ò $\pi$ otoṽv), being already in actuality what the subject is by potentiality, is

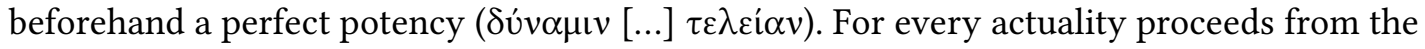
indwelling potency; if the producer ( $\tau$ ò $\pi$ oเoṽ $v$ ) should be without potency, how shall it act

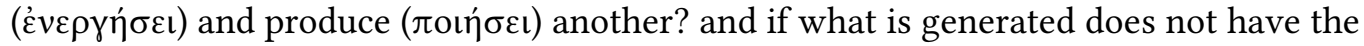
receptive potency, how may it come about? For the producer always produces that which is able to be affected, but not even any chance thing whose nature is not affected by it. (trans. Dodds, modified)

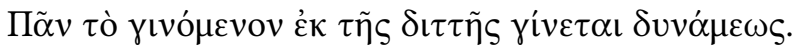

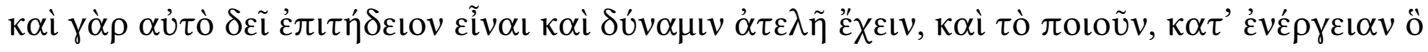

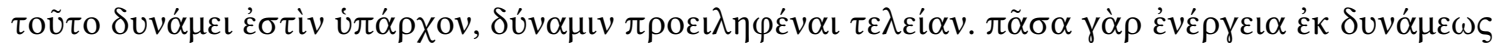

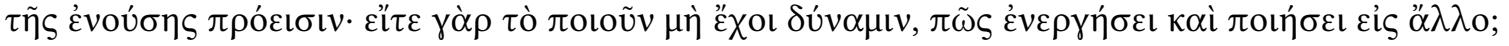

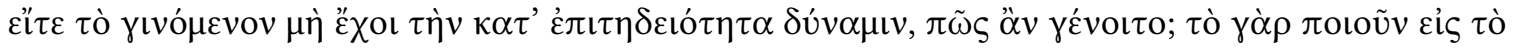

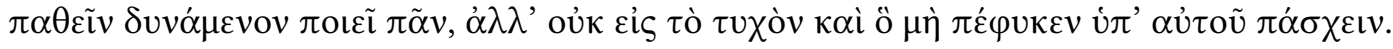

The principle that there are two kinds of potencies-perfect and imperfect $\delta$ v́v $\mu \mathrm{s}$-is essentially a

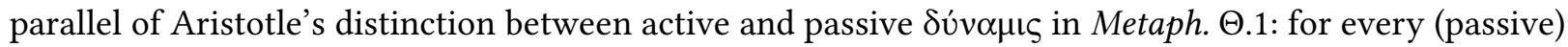
potentiality of B to be acted on by A, there is a corresponding (active) potentiality for A to act on B. Given this, all senses of passive potentiality are derived from active potentiality-which Aristotle indicates as the source of motion (paralleling the definition of efficient cause in Phys. II.3).

What's missing with Aristotle's account is that he does not anywhere explicitly, or even implicitly, affirm Proclus' principle. For Aristotle, all active potency implies actuality (at some point, if not always), but not every actuality necessarily implies active potency. This is almost certainly the case on looking at

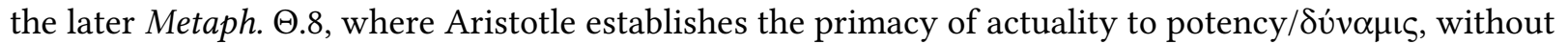
specifying which sense, if any. More so with the proof for the unmoved mover being completely in act and without any sense of potency in Metaph. $\Lambda .6$.

So with Prop. 79 [T11], by contrast to Aristotle, Proclus is thinking of actuality as contingent on having a perfect potency. This suggests that the potency itself is brought about by some prior actuality, if

\footnotetext{
${ }^{20}$ Aristotle, Phys. III.1 201a28ff.

${ }^{21}$ Aristotle, Phys. III.3 202a12-16: 'The solution of the difficulty is plain: motion is in the movable. It is the fulfilment of this potentiality by the action of that which has the power of causing motion; and the actuality of that which has the power of causing motion is not other than the actuality of the movable; for it must be the fulfilment of both. A thing is capable of causing motion because it can do this, it is a mover because it actually does it' (trans. Hardie/Gaye).
}

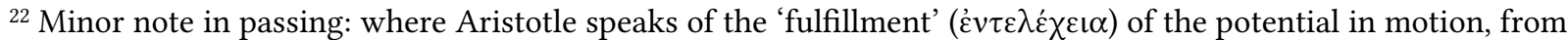
Phys. III.1, Proclus speaks of the 'perfection' ( $\tau \dot{\varepsilon} \lambda \varepsilon\llcorner o \varsigma)$ of the potential in causation. The choice of words might illustrate a subtle metaphysical difference of view, esp. if Proclus assumes qualities and perfections immanently found in things come from prior, ontologically distinct intelligible entities (i.e. Intellect, etc.). 
Proclus is being consistent and following Aristotle. ${ }^{23}$ One can easily see this, e.g.: if each particular, participated soul is in act in relation to body, that particular soul's perfect potency, from which it acts on body, must be derived from the unparticipated monad, Soul, which gives it its being-recalling ET Prop. $23[\mathrm{~T} 1]{ }^{24}$

This leads to a further distinction in causation for Proclus-the producer implanting a potency within its participant:

[T12] Proclus, Elements of Theology, Prop. 81

\begin{abstract}
All that is participated separately is present to the participant through an inseparable potency which it implants.
\end{abstract}

For if it is itself something separate from the participant and not contained in it, something which subsists in itself, then they need a mean term to connect them, one which more nearly resembles the participated principle than the participant does, and yet actually resides in the latter. For if the former is separate, how can it be participated by that which contains neither it nor any emanation from it? Accordingly a potency or irradiation, proceeding from the participated to the participant, must link the two; and this medium of participation will be distinct from both. (trans. Dodds, modified)

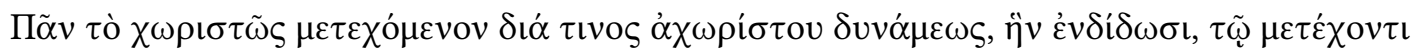
$\pi \alpha ́ \alpha \varepsilon \sigma \tau \iota \nu$.

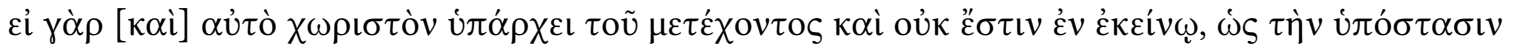

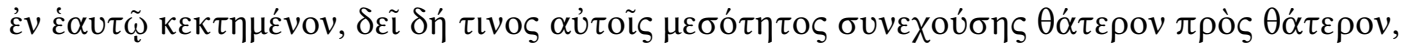

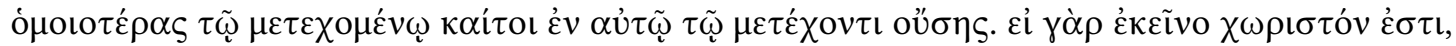

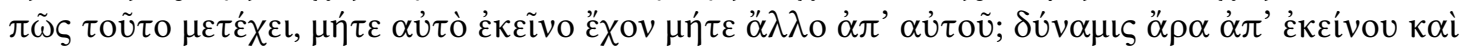

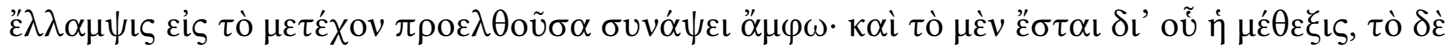

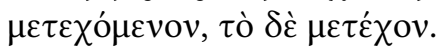

Intriguingly, we are faced with the same problem of the cause's separation as seen with the unparticipated from ET Prop. 23 [T1]. Prop. 75 [T9] made it clear that true efficient causes necessitate ontological separation and transcendence over their effects. However, immanence is also shown as necessary for action-or participation, here. So in the case of the individual, particular soul's action on

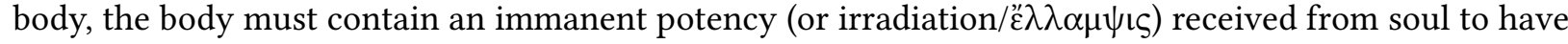
life immanent in it. Proclus states as much in the previous prop., with the necessary presence of an incorporeal in the body for body to be able to act:

[T13] ibid., Prop. 80, 11-17

Again, every agent has an active potency; but body in itself is without quality and without potency: therefore it cannot act in virtue of being body, but only in virtue of a potency of action residing in it-that is, it acts, when it does act, by participation of potency. Further, even

\footnotetext{
${ }^{23}$ Gersh (1978) also makes this point: 'Clearly this active potency could not also be described as a potency prior to act, for Proclus spoke of the cause as 'remaining in itself' while in general he views the actualization of potency as a variety of motion. In fact, when the Neoplatonists speak of the relation between cause and effect they abandon the notion that the former is being gradually actualized and, to underline the idea that it is already fulfilled before the process of causation begins, refer to it only as causing through its activity. Thus Proclus states that "producing

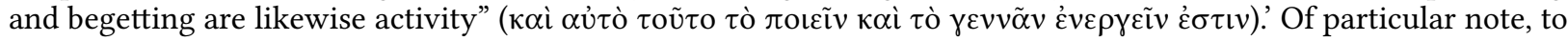
be addressed later, see ibid. n. 45: 'The notion of an actualization of potency is, however, retained when the "cause" is not yet viewed as a cause but still only as an effect of a prior term in the spiritual hierarchy'.
}

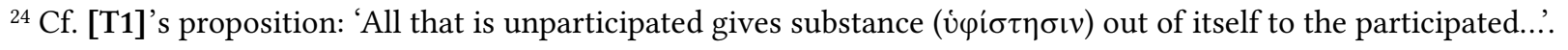


incorporeals participate passive affections when they come to be in a body, because they are then divided along with their bodies and feel the effect of the divisible nature of the latter, although in their own being they are without parts. (trans. Dodds) ${ }^{25}$

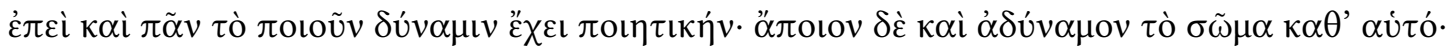

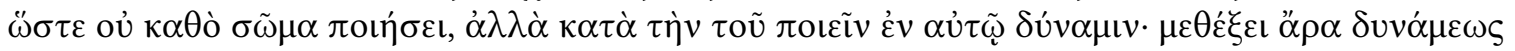

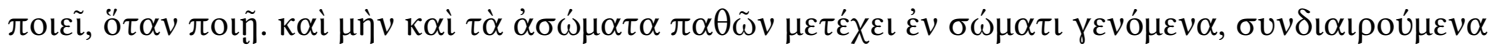

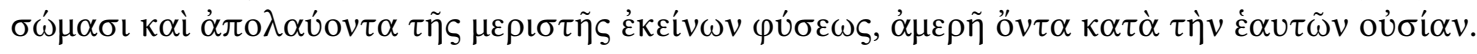

By contrast, Proclus thinks the Aristotelian causal model is insufficient, if all that is required for motion/causation is the existence of a prior source of actuality. Demonstrated in his implicit critique of the Aristotelian unmoved mover(s) of Metaph. $\Lambda .7-9:{ }^{26}$

[T14] Proclus, Commentary on Parmenides, 922.1-19

This is what we traditionally reply to those who do not make the intelligible creative causes of secondary entities: how could the heaven have appellation of the divine realm, if it be not derived from that source? Appetition would then be a result of chance, if the one is not the generative cause, and the other does not derive its existence from that quarter. As things are, it is reasonable that the thing generated should strive towards its own source and cause, and it is according to nature that the secondary should turn towards the power that creates and cognizes it. ... So that if nothing is added from the object of appellation to the appetitors, the process of appetition once again becomes superfluous, seeing that nothing can be acquired. (trans.

Morrow/Dillon)

\section{Conclusions:}

- Proclus confirms the Aristotelian thesis-all that exists potentially ( $\delta v v \alpha \dot{\alpha} \mu \varepsilon)$ is brought to act by what is already in complete actuality. [T10]

- All causality is characterized by the interaction of active and passive potency [T11]

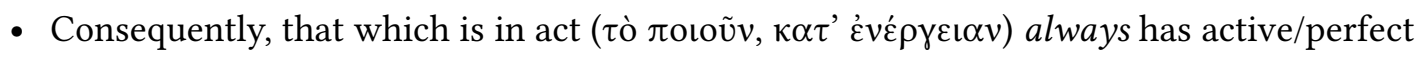
potency beforehand.

- Suggesting a descending series of potencies (e.g. unparticipated Intellect provides perfect potency for unparticipated Soul-latter itself provides perf. potency for participated soul(s)-later for bodies)

- Every cause implants an immanent potency into its effect-makes possible the actualization of the effect. [T12]

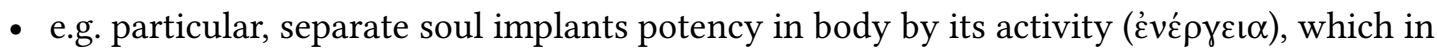
turn brings body to act as a living, acting body [T13]

In sum: The causal model of [T12] (with [T13] as specific e.g.) suggests that the two terms of cause and effect-perfect and imperfect potency [T11]-necessitates a third, intermediary term with the potency transmitted from the cause in actuality. This 'potency', which Proclus identifies as the 'incorporeal' in

\footnotetext{
${ }^{25}$ Restating Prop. 80's thesis: 'The proper nature of all bodies is to undergo action ( $\left.\pi \alpha \dot{\alpha} \sigma \varepsilon \iota v\right)$, and of all incorporeals to act ( $\pi$ oเعĩ $)$, the former being in themselves inactive: and the latter impassible; but through association with the body the incorporeal too undergoes action, even as through participation of the incorporeals

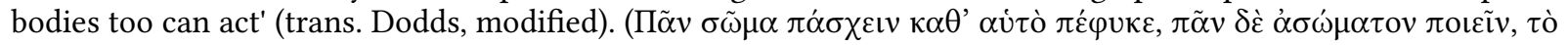

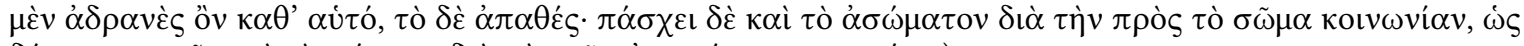

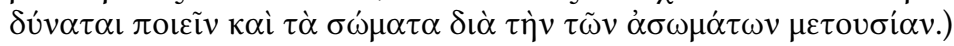

${ }^{26}$ Cf. the further analysis of Steel (1987) comparing/contrasting Proclus and Aristotle on the unmoved mover's causality.
} 


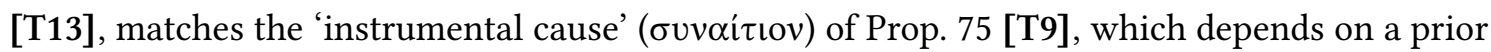
actuality.

By analogy, I now want to argue the 'participated' cause (P2) plays the same role of the transmitted 'potency' as intermediary, and therefore subordinate, between the unparticipated (P1) and receiving participants (P3):

\title{
5. Confirmation: the Unparticipated as a Primary Efficient Cause
}

\author{
[T15] Proclus, Elements of Theology, Prop. 64
}

Every monad gives rise to two series, one consisting of substances complete in themselves, and one of irradiations which have their substantiality in something other than themselves.

For if the outgoing proceeds by a declension through terms akin to the constitutive causes (prop. 28), from the wholly perfect (P1) must arise things complete in their kind (P2), and by these latter the origin of things incomplete must be mediated in due sequence: so that there will be one order of complete in themselves, and another of incomplete substances. The latter are upon such a level that they belong to their participants: for being incomplete they require a substrate for their existence. The former make the participants belong to them: for being complete they fill the participants with themselves ${ }^{27}$ and establish them in themselves, and for their substantial existence they have no need of inferior beings.

Accordingly those substances which are complete in themselves, while by their discrimination into a manifold they fall short of their original monad, are yet in some wise assimilated to it by their self-complete existence; whereas the incomplete not only as existing in another fall away from the monad which exists in itself, but also as incomplete from the all-completing monad. But all procession advances through similars until it reaches the wholly dissimilar. ${ }^{28}$ Thus each of the original monads gives rise to two series.

Cor. From this it is apparent that of the henads some proceed self-complete from the One, while others are irradiated states of unity; and of the intelligences some are self-complete substances, while others are intellectual perfections; and of souls some belong to themselves, while others belong to ensouled bodies, as being but phantasms of souls. And so not every unity is a god, but only the self-complete henad; not every intellectual property is an intelligence, but only the existential; not every irradiation of Soul is a soul, but there are also reflections of souls. (trans. Dodds)

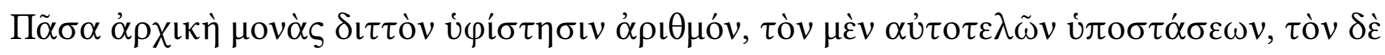

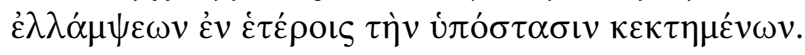

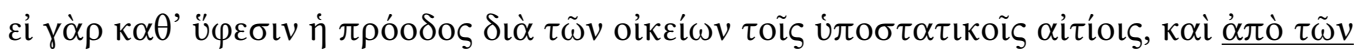

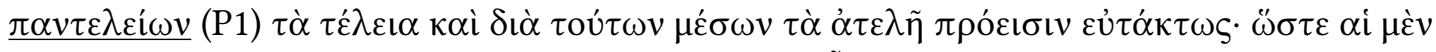

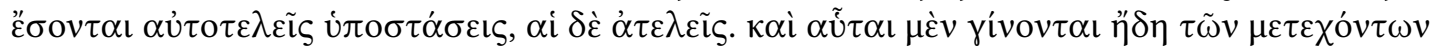

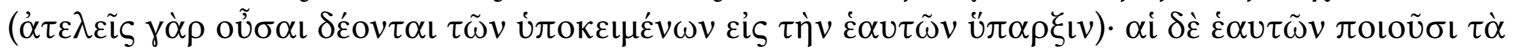

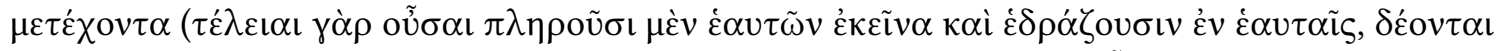

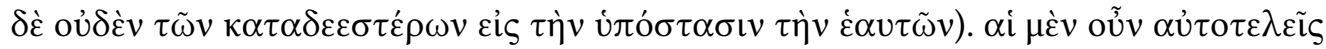

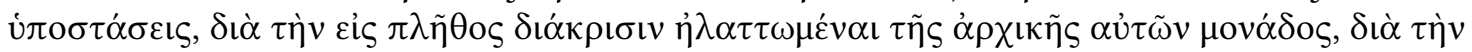

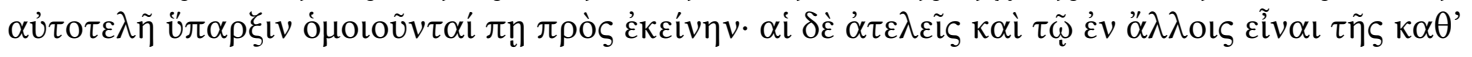

\footnotetext{
${ }^{27}$ Cf. ET Prop. 25.

${ }^{28}$ Cf. ET Prop. 28.
} 


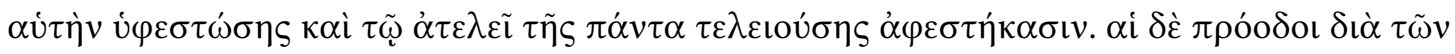

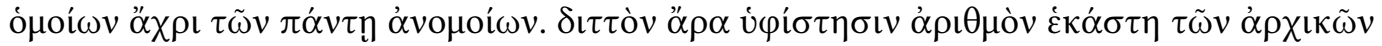
$\mu o v \alpha ́ \delta \omega v$.

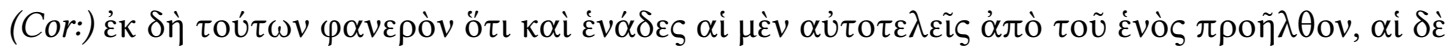

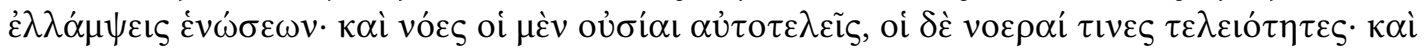

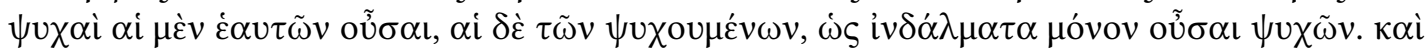

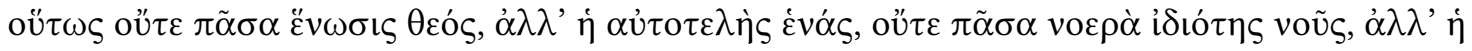

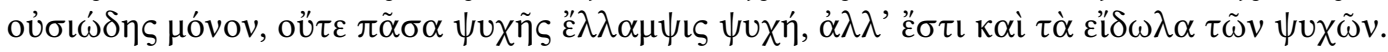

Conclusion: [T15] follows the same analogical causal structure as [T13].

- 'Wholly perfect' monads/unparticipated (P1) generate 'those complete in their own kind', yet belonging to their participants.

- The line: 'But all procession advances through similars until it reaches the wholly dissimilar' - same principle for the cause implanting immanent potency in the effect [T12].

- Participated terms (P2) are separate from participants (seen in [T1]/[T15]), unlike immanent potency in the effect.

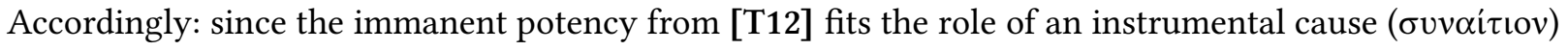
from ET Prop. 75 [T9], the participated term (P2) fits the analogical role of an instrumental cause as an intermediary between the monad/unparticipated term and the participant. [T15] confirms this approach. 


\section{References}

Barnes, Jonathan. "Immaterial Causes." Oxford Studies in Ancient Philosophy 1 (1983): 169-92.

Buchheim, Thomas. "Effective Primary Causes: The Notion of Contact and the Possibility of Acting Without Being Affected in Aristotle's De Generatione Et Corruptione," In Reading Ancient Texts: Aristotle and Neoplatonism (Vol. 2), 65-96. Leiden: Brill, 2007.

De, Rijk, LM. "Causation and Participation in Proclus: The Pivotal Role of Scope Distinction in His Metaphysics," In On Proclus and His Influence in Medieval Philosophy, edited by E. P. Bos and P. A. Meijer, 1-34. Leiden: Brill, 1992.

Gersh, Stephen. From Iamblichus to Eriugena: An Investigation of the Prehistory and Evolution of the Pseudo-Dionysian Tradition. Leiden: Brill, 1978.

Lloyd, AC. "The Principle That the Cause is Greater Than Its Effect." Phronesis (1976): 146-56.

Lowe, E.J. A Survey of Metaphysics. Oxford: Oxford University Press, 2002.

Steel, Carlos. "Proclus Et Aristote Sur La Causalité Efficiente De L’Intellect Divin," 213-25. Paris, 1987.

Steel, Carlos. "Puissance Active Et Puissance Réceptive Chez Proclus," In Dunamis Nel Neoplatonismo, edited by Francesco Romano and R. Loredana Cardullo, Firenze: La nuova Italia, 1996.

Steel, Carlos. "Neoplatonic Versus Stoic Causality: The Case of the Sustaining Cause («sunektikon»)." Quaestio 2, no. 1 (2002): 77-96.

Steel, Carlos. "Why Should We Prefer Plato's Timaeus to Aristotle's Physics? Proclus' Critique of Aristotle's Causal Explanation of the Physical World." Bulletin of the Institute of Classical Studies 46, no. S78 (2003): 175-87. 